\title{
Nilai Pendidikan Karakter Kerja Keras dalam Novel Tentang Kamu Karya Tere Liye
}

\author{
Saptiana Sulastri' ${ }^{1}$, Hariyadi ${ }^{2}$, Mai Yuliastri Simarmata ${ }^{3}$ \\ 123Program Studi Pendidikan Bahasa dan Sastra Indonesia, IKIP PGRI Pontianak, Indonesia
}

\begin{tabular}{ll}
\hline \hline & \multicolumn{1}{c}{ ABSTRACT } \\
\cline { 2 - 2 } $\begin{array}{l}\text { Keywords: } \\
\text { Values; }\end{array}$ & $\begin{array}{l}\text { Abstrak: This study aims to describe the value of hard work character education } \\
\text { in the novel About You Work Tere Liye. Research using descriptive methods with } \\
\text { Novels }\end{array}$ \\
qualitative forms. data collection techniques using documentary studies. Data \\
collection tool in this study is the researcher himself as a key instrument (human \\
instrument) assisted with other data collection tools namely data recording \\
cards. Data analysis techniques in this study used content study techniques. \\
Based on the analysis, the value of hard work character education includes hard \\
work in the family, hard work for yourself, and hard work in working.
\end{tabular}

Kata Kunci:

Nilai;

Pendidikan Karakter;

Novel

\begin{abstract}
Abstrak: Penelitian ini bertujuan untuk mendeskripsikan nilai pendidikan karakter kerja keras dalam novel Tentang Kamu Karya Tere Liye. Penelitian menggunakan metode deskriptif dengan bentuk kualitatif. Teknik pengumpulan data menggunakan studi dokumenter. Alat pengumpul data dalam penelitian ini adalah peneliti sendiri sebagai instrumen kunci (human instrument) dibantu dengan alat pengumpul data lainnya, yaitu kartu pencatat data. Teknik analisis data dalam penelitian ini menggunakan teknik kajian isi. Berdasarkan hasil analisis, nilai pendidikan karakter kerja keras meliputi kerja keras dalam keluarga, kerja keras untuk diri sendiri, dan kerja keras dalam bekerja.
\end{abstract}

Correspondance address:

E-mail: saptianasulastri292@gmail.com (Saptiana Sulastri)

\section{Pendahuluan}

Pendidikan merupakan upaya membangun kecerdasan, baik kognitif, afektif, maupun psikomotorik. Oleh karenanya, pendidikan secara terus-menerus dibangun dan dikembangkan agar menghasilkan generasi yang unggul baik dalam ilmu, iman, dan amal. Suatu bangsa pastinya tidak ingin menjadi bangsa yang tertinggal atau terbelakang. Berbagai upaya dilakukan pemerintah untuk kemajuan bangsanya. Untuk menghadapi kecanggihan teknologi dan komunikasi yang terus berkembang, perbaikan sumber daya manusia juga perlu terus diupayakan untuk membentuk manusia yang cerdas, terampil, mandiri, dan berakhlak mulia. Salah satu yang sedang dicanangkan akhir-akhir ini dalam dunia pendidikan adalah pendidikan karakter. Amin (2013) menyatakan "karakter adalah hal yang unik dan khas yang merupakan pembeda antara anak yang satu dengan anak yang lain dalam berucap dan berperilaku.

Pendidikan karakter hadir sebagai jawaban atas peristiwa yang terjadi pada akhir-akhir ini sangatlah memprihatinkan karena kecenderungan merosotnya moral bangsa hampir terasa di semua strata kehidupan. Krisis moral ini kemudian diikuti dengan menyuburnya pola hidup konsumtif, materialistis, hedonis, dan lain sebagainya yang semuanya menyebabkan tersingkirnya rasa kemanusiaan, kebersamaan, dan kesetiakawanan sosial. Khusus di kalangan mahasiswa, problema sosial moral ini dicirikan dengan sikap arogansi, rendahnya kepedulian sosial, saling memfitnah sesama 
teman, hingga merosotnya penghargaan dan rasa hormat terhadap orang tua dan dosen sebagai sosok yang seharusnya disegani dan dihormati. Tantangan tersebut merupakan ujian berat yang harus dilalui dan dipersiapkan oleh seluruh warga Indonesia. Kunci sukses dalam menghadapi tantangan berat itu terletak pada kualitas sumber daya manusia yang handal dan berbudaya.

Dasar pemikiran gerakan pendidikan karakter ialah bahwa perilaku-perilaku menyimpang yang setiap hari membombardir, seperti kekerasan, ketamakan, korupsi, ketidak sopanan, ketidakadilan, perampasan, dan etika kerja yang buruk, yang pada intinya tidak adanya karakter yang baik. Hal ini dikarenakan akar dari semua tindakan yang jahat dan buruk, tindak kejahatan, terletak pada hilangnya karakter. Semuanya terasa lebih kuat ketika negara ini dilanda krisis dan tidak kunjung beranjak dari krisis yang dialami.

Alasan peneliti memilih pendidikan karakter, yaitu dengan mempertimbangkan bahwa pendidikan karakter sangat diperlukan untuk generasi bangsa dalam kehidupan bermasyarakat, bangsa, dan negara Indonesia. Pendidikan karakter bertujuan untuk menguatkan dan mengembangkan nilai-nilai kehidupan yang dianggap penting sehingga menjadi kepribadian yang berguna bagi bangsa dan negara Indonesia.

Ada banyak media yang dapat dijadikan bahan untuk pengajaran nilai pendidikan karakter. Salah satunya adalah karya sastra. Simarmata (2017) menjelaskan pendidikan karakter bertujuan mengembangkan kemampuan, membentuk watak dan peradaban bangsa bermartabat untuk mencerdaskan kehidupan bangsa. Rahman dan Suyitnno (2016) mengatakan bahwasanya "mengenalkan pendidikan karakter bisa melalui pembelajaran, salah satunya pembelajaran sastra". Dalam hal ini, karya sastra sangat bermanfaat bagi kehidupan karena karya sastra dapat memberikan kesadaran keadaan pembaca tentang kebenaran-kebenaran hidup, walaupun dilukiskan dalam bentuk fiksi. Karya sastra dapat memberikan kegembiraan dan kepuasan batin. Hiburan ini adalah jenis hiburan intelektual dan spriritual. Salah satu diantara karya sastra itu adalah novel.

Novel merupakan suatu karangan prosa yang bersifat cerita, yang menceritakan suatu kejadian yang luar biasa dari kehidupan tokoh di dalam cerita. Kosasih (2011) menjelaskan "novel adalah karya imajinatif yang mengisahkan sisi utuh problematika kehidupan seseorang atau beberapa orang tokoh hingga tahap penyelesaiannya". Dikatakan kejadian yang luar biasa karena kejadian itulah lahir suatu konflik, suatu pertikaian, yang mengalihkan salah satu dari segi kehidupan sang tokoh yang benarbenar istimewa yang mengakibatkan terjadinya perubahan nasib.

Novel terdiri atas unsur-unsur pembangun, yaitu unsur intrinsik dan ekstrinsik. Unsur Intrinsik adalah unsur struktur formal yang membangun karya sastra dari dalam. Unsur-unsur tersebut antara lain tema, alur, latar, tokoh, penokohan atau perwatakan, dan gaya bahasa. Unsur ekstrinsik adalah unsur yang berada di luar karya sastra yang mempengaruhi terciptanya karya tersebut.

Dorongan peneliti untuk meneliti novel sebagai objek yang dianalisis karena novel merupakan satu diantara bentuk karya sastra yang sebagian besar objek penceritaannya tentang fenomena kehidupan manusia baik fakta maupun khayalan yang menarik untuk diceritakan dan dapat diambil pelajaran dari kisah hidup manusia di dalam novel. Melalui novel, pembaca menemukan dan mengetahui promblematika kehidupan suatu masyarakat. Salah satu novel yang menarik dan banyak mengandung nilai pendidikan karakter kerja keras adalah novel Tentang Kamu karya Tere Liye. Novel Tentang Kamu karya Tere Liye berisi kisah perjalanan hidup seseorang untuk mendapatkan keadilan serta kedamaian dalam kesabaran dan keikhlasannya. Kajian terhadap novel Tentang Kamu karya Tere Liye pernah dilakukan oleh Apriyani (2018) dengan mengkaji aspek kepribadian tokoh dalam novel. Eswanti dan Sunanta (2018) juga pernah mengkaji novel tersebut dengan melakukan tinjauan sosiologi sastra untuk melihat implementasinya sebagai bahan ajar. Lusiana, Subadiyono, \& Suhendi (2018) meniliti tentang citra perempuan dalam novel tersebut. Dapat dilihat bahwa penelitian terhadap novel Tentang Kamu karya Tere Liye belum ada yang mengangkat tentang nilai karakter dalam novel, karena itu, peneliti tertari untuk melakukannya.

Terpilihnya nilai kerja keras dalam novel Tentang Kamu karena nilai kerja keras sangat penting bagi setiap individu sebagai dasar untuk menjalani kehidupan yang sangat keras dengan berbagai macam dinamika kehidupan. Hidayatullah (2010) menjelaskan bahwa "kerja keras adalah sebagai kemampuan mencurahkan atau mengerahkan seluruh usaha dan kesungguhan, potensi yang dimiliki 
sampai akhir masa suatu urusan hingga tujuan tercapai”. Kesuma, dkk, (2012) mengatakan bahwa karakteristik kerja keras merupakan perilaku seseorang yang diciri-cirikan oleh kecenderungan sebagai berikut: 1) merasa risau jika pekerjaannya belum terselesaikan sampai tuntas; 2) mengecek atau memeriksa terhadap apa yang harus dilakukan atau apa yang menjadi tanggung jawabnya dalam suatu jabaran/posisi; 3) mampu mengolah waktu yang dimilikinya; dan 4) mampu mengorganisasikan sumber daya yang ada untuk menyelesaikan tugas dan tanggung jawab.

Peneliti berharap, dengan adanya penelitian ini dapat membantu membentuk nilai pendidikan karakter kerja keras kepada peserta didik melalui media karya sastra yaitu novel. Sehingga penelitian ini dapat memberikan kontribusi bagi dunia pendidikan dalam membentuk akhlak peserta didik yang mulia dan bermartabat.

\section{Metode}

Metode merupakan aspek yang berpengaruh besar serta sangat penting terhadap hasil suatu penelitian. Metode yang digunakan dalam penelitian ini adalah metode deskriptif. Metode deskriptif adalah metode yang dilakukan dengan cara mendeskripsikan fakta-fakta yang kemudian disusul dengan analisis. Nawawi (2012: 67) mengemukakan "metode deskriptif adalah prosedur pemecahan masalah yang diselidiki dengan menggambarkan /melukiskan keadaan subyek penelitian (seseorang, lembaga, masyarakat, dan lain-lain) pada saat sekarang berdasarkan fakta-fakta yang tampak atau sebagaimana adanya.

Adapun data dalam penelitian adalah kutipan berupa narasi dan dialog yang berhubungan dengan nilai pendidikan karakter kerja keras, kreatif, dan mandiri yang terdapat dalam novel Tentang Kamu karya Tere Liye. Sumber data dalam penelitian ini adalah novel Tentang Kamu karya Tere Liye. Novel ini diterbitkan pada tahun 2016 oleh Republika Penerbit cetakan ke-2, terdiri dari 33 Bab dengan 524 jumlah halaman. Zuldafrial (2011:54) menyatakan bahwa "sumber data dalam penelitian adalah subjek dari mana data dapat diperoleh.

Teknik pengumpulan data menggunakan teknik studi dokumenter dibantu dengan alat pencatat data. Teknik Studi dokumenter, yakni Nawawi (2012) mengemukakan "teknik studi dokumenter adalah cara mengumpulkan data melalui peninggalan tulisan, terutama berupa arsiparsip dan termasuk juga buku-buku tentang pendapat, teori, dalil/hukum dan lain-lain yang berhubungan dengan masalah penyelidik. Penelitian ini menggunakan teknik studi dokumenter yakni dengan cara menelaah teks sebuah karya sastra. Penelaahan dilakukan dengan cara mengklasifikasikan bagian-bagian yang menjadi objek penelitian dalam penelitian ini, khususnya nilai-nilai pendidikan karakter dalam novel Tentang Kamu karya Tere Liye. Pengklasifikasian tersebut dimaksudkan untuk memisahkan bagian-bagian yang termasuk sebagai data yang akan dianalisis sehingga mempermudah peneliti dalam menghubungkannya dengan masalah serta tujuan yang ada dalam penelitian ini.

Alat pengumpul data adalah alat bantu yang digunakan oleh peneliti dalam kegiatannya mengumpulkan data agar kegiatan tersebut menjadi sistematis dan dipermudahkan olehnya. Alat pengumpul data dalam penelitian ini adalah peneliti sendiri sebagai instrument kunci (human instrumen). Sugiyono (2017:102) "human instrument berfungsi menetapkan fokus penelitian, memilih informan sebagai sumber data, melakukan pengumulan data, menilai kualitas data, analisis data, menafsirkan data dan membuat kesimpulan atas temuannya".

Teknik analisas data adalah penguraian data atas berbagai bagiannya dan penelaahannya. Teknik analisis data dalam penelitian ini menggunakan content analysis atau teknik analisis isi penelitian ini merupakan penelitian kualitatif. Menurut Ismawati (2012) menjelaskan "content analysis adalah sebuah teknik penelitian untuk membuat inferensi- inferensi dengan mengidentifikasi secara sistematis dan objektif karakteristi-karakteristik khusus dalam sebuah teks". 


\section{Hasil dan Pembahasan}

Kerja keras adalah kunci utama untuk meraih kesuksesan dan kebahagiaan dalam hal apapun. Sudah pasti kita memperoleh sesuatu dengan usaha dan kerja keras yang kita lakukan. Kerja keras bukanlah sesuatu yang mudah dikerjakan diperlukan sebuah tekad yang kuat untuk mewujudkannya.

\section{Kerja Keras dalam Membantu Keluarga}

Adapun kerja keras dalam lingkungan keluarga terdapat dalam novel Tentang Kamu karya Tere Liye data dilihat pada beberapa kalimat berikut.

\section{Data 1}

Sri menggeleng perlahan. Dia tidak bisa pulang jika embernya belum penuh., dia tidak tahu harus sampai jam berapa. Satu tahun sejak kepergian bapaknya, bukannya hanya harus membantu pekerjaan rumah, mengepel, mencuci, menyetrika, memasak, dia harus bekeria mencari uang. Mencari teripang, ikan, kerang, atau tetehe (bulu babi) di laut dangkal sekitar Pulau Bungin adalah pekerjaan itu, sejak jam satu siang dia mencari teriang, membawa ember. Jadi tadi siang tubuhnya disiram terik matahari, malam ini badannya dingin diterpa angin malam (Liye, 2016:106).

Berdasarkan hasil penelitian kutipan narasi pada data 1, kalimat yang menunjukan kerja keras dalam keluarga dapat dilihat dari kalimat "Satu tahun sejak kepergian bapaknya, bukannya hanya harus membantu pekerjaan rumah, mengepel, mencuci, menyetrika, memasak, dia harus bekerja mencari uang. Mencari teripang, ikan, kerang, atau tetehe (bulu babi) di laut dangkal sekitar Pulau Bungin adalah pekerjaan itu". Kalimat tersebut terlihat bagaimana perjuangan Sri Ningsih. Bekerja keras mulai dari membersihkan rumah serta memasak. Sri Ningsih yang bekerja keras demi mendapatkan uang sejak jam satu siang dia mencari teripang, membawa ember. Siang tubuhnya disiram terik matahari, malam badannya dingin diterpa angin malam. Sri Ningsih selalu berusaha bekerja keras dan giat karena hanya itu yang bisa ia lakukan untuk ibu tiri dan adik tirinya.

\section{Data 2}

Sri sebenarnya sudah amat lelah, apalagi kemarin malam dia juga tidur di bawah tampias hujan, tambahkan sepanjang siang mencari kerang. Sri menggigit bibir, membujuk agar tangannya terus kuat mendayung melawan ombak kencang. Perutnya juga keroncongan, terakhir dia makan adalah tadi pagi bersama Tilamuta. Gadis kecil itu menyeka peluh di pelipis, tidak ada waktu untuk memikirkan perutnya. Bukankah tadi dia hendak memasakan kerang saus pedas buat Tilamuta? Semakin cepat dia kembali membawa air bersih, semakin baik. Semoga adiknya belum tertidur - sambil kelaparan (Liye, 2016:120).

Berdasarkan hasil penelitian kutipan narasi pada data 2, kalimat yang menunjukan kerja keras dalam keluarga dapat dilihat dari kalimat "Gadis kecil itu menyeka peluh di pelipis, tidak ada waktu untuk memikirkan perutnya. Bukankah tadi dia hendak memasakan kerang saus pedas buat Tilamuta?" Kalimat tersebut menjelaskan tentang kerja keras seorang kakak tiri untuk tidak membiarkan adik tirinya tidur dalam keadaan kelaparan. Sri Ningsih, selalu berusaha dan bekerja keras tanpa memperdulikan keadaan dirinya yang lelah karena bekerja siang dan malam.

\section{Data 3}

Sri menghentakan tangannya, berhasil, pegangan itu lepas. Dia tidak peduli, dia harus'menyelamatkan Tilamuta dan Nusi Maratta. Sebelum pemuda lain berhasil mencegahnya, Sri berlari menaiki anak tangga. Puluhan penduduk Pulau Bungin menatap terpana. Satu-dua ibu-ibu menjerit nyeri. Tanpa ragu Sri lompat ke gelanggan kobaran api (Liye 2016:134).

Berdasarkan hasil penelitian kutipan narasi pada data 3, kalimat yang menunjukan kerja keras dalam keluarga dapat dilihat dari kalimat "Tanpa ragu Sri lompat ke gelanggan kobaran api". Kalimat peristiwa diatas menjelaskan sikap kerja keras Sri Ningsih. Sikap kerja keras Sri Ningsih, pengorbanannya demi menyelamtkatkan ibu tiri dan adik tirinya sangat jelas terlihat. Dia tidak peduli 
dengan kobaran api yang akan membakar hangus kulitnya, yang dia pikirkan hanya bagaimana bisa`menyelamatkan ibu tiri dan adik tirinya yang terkurung di dalam kamar dengan kobaran api yang sangat ganas.

\section{Kerja Keras untuk Diri Sendiri}

Adapun kerja keras untuk diri sendiri terdapat dalam novel Tentang Kamu karya Tere Liye dapat dilihat pada beberapa kalimat berikut.

\section{Data 1}

"Kami tidak tahu sama sekali jika ibu Sri Ningsih baru saja melakukan perjalanan ratusan kilometer dari London sepanjang malam. Dia ... Dia tidak punya sepeser uang pun, menumpang dari satu mobil ke mobil lain. Termasuk saat menyeberangi selat Inggris, dia menumpang perahu nelayan, karena ferry tidak mau menaikan penumang tanpa tiket. Tiba didaratan Perancis, dia kembali menumpang mobil demi mobil, hingga akhirnya tiba dipinggiran kota Paris." (Liye, 2016:34).

Berdasarkan hasil penelitian, kalimat yang menunjukan kerja keras untuk diri sendiri dapat dilihat dari kalimat "Dia ... Dia tidak punya sepeser uang pun, menumpang dari satu mobil ke mobil lain". Berdasarkan kalimat tersebut menceritakan perjuangan Sri Ningsih. Bekerja keras, melakukan perjalanan jauh dari kota London hingga kota Paris. Tidak punya sepeser uang pun, menumpang dari satu mobil ke mobil yang lain serta menumpang perahu nelayan. Kerja keras sangat dibutuhkan agar kemauan dan keinginan kita terwujud.

\section{Data 2}

Pak Tua mengusap rambut putihnya.

"Aku sedih sekali mendengar kabar Sri telah meninggal ... Tapi Masya Allah, ini sekaligus berita yang indah. Aku tahu sejak dulu, Sri akan melakukan hal-hal hebat. Dia tidak akan menghabiskan usianya di Pulau Bungin ... Paris? Bukan main. Dia telah mengelilingi dunia. Jika demikian dia meninggal dengan menggapai cita-citanya. Juga cita-cita Rahayu, ibunya." (Liye, 2016:139).

Berdasarkan hasil penelitian, kalimat yang menunjukan kerja keras untuk diri sendiri dapat dilihat dari kalimat "Jika demikian dia meninggal dengan menggapai cita-citanya. Juga cita-cita Rahayu, ibunya". Berdasarkan kalimat tersebut menjelaskan bahwa kerja keras Sri Ningsih mewujudkan citacitanya telah berhasil. Dia telah mengelilingi dunia. Dia berhasil menaklukan dunia yang luas. Dengan keyakinannya Sri Ningsih untuk terus berusaha menggapai segala keinginan dan cita-citanya untuk mengelilingi dunia tanpa mengenal rasa lelah.

\section{Data 3}

Saat kita sudah melakukan yang terbaik dan tetap gagal, apa yang harus kita lakukan? Berapa kali kita harus mencoba hingga tahu bahwa kita telah tiba pada batas akhirnya? 2x, 5x, 10x atau berpuluh-puluh kali hingga kita tak dapat menghitung lagi? Berapa kali kita harus menerima kenyataan, untuk tahu bahwa kita memang tidak berbakat, sesuatu itu bukan jalan hidup kita, lantas melangkah mundur? Aku sekarang tahu jawabannya. Di sini, di kota yang sibuk mengejar dan di kejar pembangunan, gedung-gedung tinggi tumbuh seperti jamur dimusim hujan. Disini, di kota tempat harapan ribuan pendatang, Tiap hari terminal, stasiun padat oleh penduduk baru. Lampu-lampu gemerlap, jalan-jalan luas, kawasan hijau yang semakin habis, orang-orang mengejar mimpi. Terimakasih atas perjalanan tentang keteguhan. Aku tahu sekarang, pertanyaan terpentingnya buka berapa kali kita gagal, melaikan berapa kali kita bangkit lagi, lagi dan lagi setelah gagal tersebut (Liye, 2016:210).

Berdasarkan hasil penelitian, kalimat yang menunjukan kerja keras untuk diri sendiri dapat dilihat dari kalimat "Aku tahu sekarang, pertanyaan terpentingnya buka berapa kali kita gagal, melaikan berapa kali kita bangkit lagi, lagi dan lagi setelah gagal tersebut". Penggambaran sikap kerja keras yang dilakukan oleh Sri Ningsih terlihat di dalam kalimat di atas. Sikap Sri Ningsih yang berani bangkit berulang-ulang, lagi dan lagi, setelah segala kegagalan yang terjadi. Yang terpenting bukan 
seberapa kali kita gagal tetapi seberapa berani kita bangkit untuk memperbaiki kegagalan. Kerja keras yang dilakukan Sri Ningsih mengajarkan arti perjuangan dengan keteguhan hati yang kokoh.

\section{Data 4}

Menurut rencanaku, jika semua berjalan lancar, akhir tahun ini aku akan punya armada yang cukup untuk mengurus izin perusahaan taksi resmi, dan usaha ini bisa berkembang lebih cepat lagi, aku semangat sekali, selalu bangun pukul empat pagi, memastikan semua mobil siap, memeriksa daftar pesanan, mengawasi semuanya, baru tidur pukul dua belas malam, setiap hari, setiap minggu, tidak pernah bersantai (Liye, 2016:249).

Berdasarkan hasil penelitian, kalimat yang menunjukan kerja keras untuk diri sendiri dapat dilihat dari kalimat "Selalu bangun pukul empat pagi, memastikan semua mobil siap, memeriksa daftar pesanan, mengawasi semuanya, baru tidur pukul dua belas malam, setiap hari, setiap minggu, tidak pernah bersantai". Menghargai waktu, salah satu karakter pekerja keras. Pada kalimat di atas menjelaskan Sri Ningsih tidak pernah bersantai, memanfaatkan waktu semaksimal mungkin.

\section{Kerja Keras dalam Bekerja}

Adapun kerja keras dalam bekerja terdapat dalam novel Tentang Kamu karya Tere Liye data dilihat pada beberapa kalimat berikut.

\section{Data 1}

Ternyata mencari bekerjaan di Jakarta susah Nur. Kata siapa mudah. Setiap hari mulai pukul tujuh pagi aku berialan kaki tiada henti menelusuri jalan, terik matahari membakar kepala, keluar masuk bangunan, baru sorenya menjelang malam aku pulang. Tetap gagal puluhan tempat ku datangi, semuanya menolakku. Aku harus semakin berhemat, jika awalnya tidak naik oplet, sekarang aku tidak makan siang, cukup sarapan seadanya, dan baru malamnya aku makan nasi (Liye 2016:219).

Berdasarkan hasil penelitian, kalimat yang menunjukan kerja keras dalam bekerja dapat dilihat dari kalimat "Setiap hari mulai pukul tujuh pagi aku berjalan kaki tiada henti menelusuri jalan, terik matahari membakar kepala, keluar masuk bangunan, baru sorenya menjelang malam aku pulang". Kalimat tersebut menceritakan tentang kerja keras Sri Ningsih dalam mencari pekerjaan harus berjalan dan berkeliling kota Jakarta. Sri Ningsih yang selalu gian mencari pekerjaan dari pagi hingga malam dia tidak pernah mengeluh dan selalu terus bekerja keras mencari pekerjaan. Semangat yang tinggi, itu yang membuatnya mampu melewati rintangan yang sulit.

\section{Data 2}

Tiga bulan berlalu, aku semakin cemas, tabunganku sudah sangat mengkhawatirkan. Lebih-lebih, aku sakit diawal bulan itu. Demam tipes. Tubuhku jadi kurus, rambutku jadi rontok, kamu tidak akan suka melihatnya. Separuh semangatku runtuh. Kadang aku berpikir, mungkin sebaiknya kembali ke Surakarta. Tapi keinginan mencoba hal baru, melakukan hal-hal baru, membuatku kembali mengurungkan niat, siapa tahu akhirnya ada jalan setelah sembuh, sambil mencari pekerjaan tetap, aku bekerja serabutan di pasar agar dapat bertahan lebih lama. Menjaga kios, menjadi kuli angkut, kamu akan tertawa melihatku memikul karung beras, disuruh ini itu, apa saja sepanjang aku bisa makan (Liye 2016:220).

Berdasarkan hasil penelitian, kalimat yang menunjukan kerja keras dalam bekerja dapat dilihat dari kalimat "Menjaga kios, menjadi kuli angkut, kamu akan tertawa melihatku memikul karung beras, disuruh ini itu, apa saja sepanjang aku bisa makan". Kalimat di atas mendeskripsikan tentang sikap kerja keras yang dilakukan oleh Sri Ningsih. Tanpa pernah mengeluh, Sri Ningsih membanting tulang memenuhi kebutuhan hidup. Walaupun harus menjadi kuli angkut. Semua dilakukan hanya agar kebutuhan hidup terpenuhi. 


\section{Data 3}

Bisnis sewa mobilku juga maju pesat. Sejak tahun terakhirku enam bulan lalu, aku sudah menambah enam mobil lagi, total sekarang dua belas mobil. Aku merekrut banyak sopir baru (Liye, 2016:246).

Berdasarkan hasil penelitian, kalimat yang menunjukan kerja keras dalam bekerja dapat dilihat dari kalimat "Bisnis sewa mobilku juga maju pesat". Melalui kalimat di atas menggambarkan sikap kerja keras yang dilakukan Sri Ningsih, yang membuat usaha sewa mobilnya maju pesat.

\section{Data 4}

Tekadku sudah bulat. Bismillah, sebulan lalu aku membeli lahan kosong di sekitar Pulogadung. Harga tanah disini masih murah dibanding Pasar Senen. Lantas lahan kosong itu aku jaminkan ke bank, untuk memperoleh pinjaman. Bankingnya sudah kenal denganku, relasi pabrik sebelumnya. Mereka menyetujui rencanaku, mamberikan kredit. Bulan-bulan ini tukang sedang membangun pabrik dan kantor, aku juga sudah memesan peralatan, mesin-mesin dan bahan mentah, sekaligus, membuka lowongan pekerjaan. Semoga paling telat, enam bulan lagi kami sudah beroperasi (Liye 2016:260-261).

Berdasarkan hasil penelitian, kalimat yang menunjukan kerja keras dalam bekerja dapat dilihat dari kalimat "Tekadku sudah bulat". Berdasarkan kalimat di atas menjelaskan sifat kerja keras Sri Ningsih dengan tekad yang kuat yang tidak bisa digoyahkan. Semangat yang menggebu-gebu Sri Ningsih membuka usaha baru, yaitu pabrik sabun. Sri Ningsih bekerja keras untuk operasi pertama sabunnya agar berjalan sesuai rencana.

\section{Simpulan}

Berdasarkan hasil penelitian, dapat disimpukan bahwa nilai kerja keras dalam Novel Tentang Kamu karya Tere Liye meliputi kerja keras dalam keluarga, kerja keras untuk diri sendiri, dan kerja keras dalam bekerja. Muatan tersebut tercermin dalam perilaku tokoh yang digambarkan dalam novel. Karena itu, novel ini dapat menjadi salah satu bahan dalam pembelajaran pendidikan nilai karakter kerja keras.

\section{Daftar Pustaka}

Amin, Maswardi Muhammad. 2011. Pendidikan Karakter Anak Bangsa. Jakarta: Baduose Media.

Afriyani, I. 2018. Aspek Kepribadian Tokoh Utama dalam Novel Tentang Kamu Karya Tere Liye. Stilistika: Jurnal Pendidikan Bahasa dan Sastra, 10(1).

Eswanti, R. D., \& Sunanda, A. 2018. Nilai Moral Dalam Novel Tentang Kamu Karya Tere Liye: Tinjauan Sosiologi Sastra Dan Implementasinya Sebagai Bahan Ajar Di SMA (Doctoral dissertation, Universitas Muhammadiyah Surakarta).

Hidayatullah, M Furqon. 2010. Pendidikan Karakter: Membangun Peradaban Bangsa. Surakarta: Yuma Pustaka.

Ismawati, Esti. 2012. Metode Penelitian Bahasa dan Sastra. Surakarta: Yuma Pustaka.

Kosasih. 2011. Ketatabahasaan dan Kesusastraan. Bandung: Yrama Widya.

Kesuma, Dharma, dkk. 2012. Pendidikan Karakter: Kajian Teori dan Praktik di Sekolah. Bandung: PT Remaja Rosdakarya.

Liye, Tere. 2016. Tentang Kamu. Jakarta: Republika.

Lusiana, L., Subadiyono, S., \& Suhendi, D. (2018). Citra Perempuan dalam Novel Tentang Kamu Karya Tere Liye dan Novel Cermin Jiwa Karya S. Prasetyo Utomo (Doctoral dissertation, Sriwijaya University). 
50 Jurnal Penelitian dan Pengembagan Sains dan Humaniora, Vol 4(1) April 2020, h. 43-50

Nawawi, H. 2012. Metode Penelitian Bidang Sosial. Yogyakarta: Gajah Mada University Press.

Rahman, Adenarsy Avereus dan Suyitno, Herman. 2016. "Analisis Psikologis Tokoh dan Nilai Pendidikan Karakter Pada Novel Amba Karya Laksmi Pamunjak Serta Relevansinya Dalam Pembelajaran Sastra Di Perguruan Tinggi". Jurnal S2 Pendidikan Bahasa Indonesia, vol.1, no.1, hlm.10-21.

Simarmata, M. Y., \& Agustina, R. 2017. "Kefektifan Bahan Ajar Berbasis Pendidikan Karakter untuk Meningkatkan Kesantunan Tindak Tutur Imperatif". JP-BSI (Jurnal Pendidikan Bahasa dan Sastra Indonesia), vol.2, no.2, hlm. 41-43.

Sugiyono. (2017). Metode Penelitian Kualitatif. Bandung: Alfabeta

Zuldafrial. (2011). Penelitian Kualitatif. Pontianak: STAIN Pontianak Press. 